\title{
Effect of Numbers of Fringing Electric Field (FEF) Fingers on the Performance of Sensor for Water Content in Soil
}

\author{
Mohd Farizul Azman, Azmi Yahya, and Hadi Purwanto
}

\begin{abstract}
The Fringing Electric Field (FEF) element design consideration has been discussed in this paper. This type of sensor is planned to be used for the Non-Destructive Test (NDT) measurement of a moisture level in soil for irrigation system in the field and green house. The effect of soil type and its moisture level has been taken into account by preparing several types of soil moisture level in the lab by performing measurement and calculation as proposed by several papers. It has been shown that the FEF parameters such as the dielectric constant, numbers of finger for FEF design and the working frequency played an important role for FEF design considerations. The performance of the FEF element sensor had been compared with the commercial sensor for benchmarking.
\end{abstract}

Index Terms-FEF, fringing electric field, MUT, material under test, NDT, non-destructive test, PCB, printed circuit board, PPC, parallel plate capacitor, VWC, volumetric water content.

\section{INTRODUCTION}

Fringing electric field (FEF) soil moisture sensor use printed circuit board (PCB) technology as the sensor platform and is fabricated on the selected PCB material. The electrical capacitance of sensor uses the soil as a dielectric which depends on the soil water content. The measurement is done at a fixed frequency. Soil consists of air, water and solids as shown in Fig. 1.

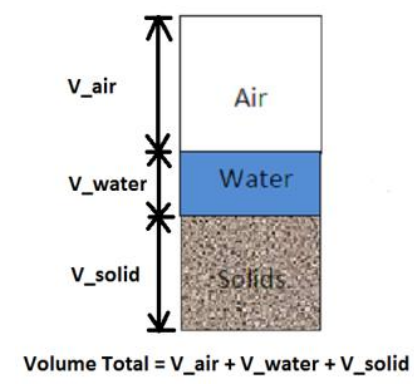

Fig. 1. Elements of soils.

Volumetric water content (VWC) of soil is the ratio of the volume of water over the total value of soil. Volumetric water content, $\theta$, is defined mathematically as:

Manuscript received December 5, 2012; revised February 6, 2013.

Mohd Farizul Azman and Azmi Yahya are with the Department of Green Technology and Engineering Support in MIMOS Berhad, Technology Park Malaysia, 57000 Kuala Lumpur, Malaysia (e-mail: \{farizul.azman, azmiya\}@mimos.my).

Hadi Purwanto is with the Faculty of Engineering, International Islamic University of Malaysia, Jalan Gombak, 53100 Kuala Lumpur, Malaysia (e-mail: hadi@iium.edu.my).

$$
\theta=V_{W} / V_{T}
$$

where $V_{W}$ is the volume of water and $V_{T}=V_{\text {soil }}+V_{\text {water }}+V_{\text {air }}$ is the total volume. The operating principle of a fringing electric field (FEF) sensor can be understood in terms of the more conventional parallel plate capacitor (PPC), which is commonly used to measure dielectric properties of materials. Fig. 2 shows a gradual transition from the PPC to a fringing field capacitor. The electrodes of the fringing field capacitor are open up to provide one sided access to material under test (MUT). Therefore the sensor can be fabricated on PCB and it can access the soil from single side.

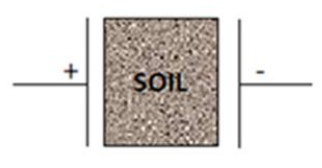

Parallel plate capacitor

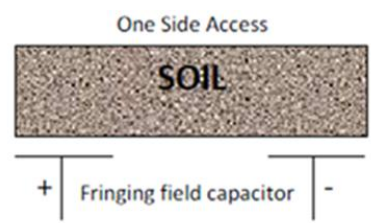

Fig. 2. Transition from PPC to fringing filed capacitor.
Soil moisture would change the relative permittivity of the capacitor. Therefore, changes in VWC of the soil would change the capacitance of the sensor. The FEF sensor in this study is comprised of two set coplanar electrodes which are excitation electrode and sensing electrode. The electric fields originating from the driving electrodes will penetrate through the soil and then terminate on the sensing electrodes. The dielectric properties of the soil will alter the distribution of the electric field lines. The capacitance on the sense electrodes is then measured using precision LCR meter.

Because the electric field of the sensors is non-uniform, the measurement sensitivity becomes position-dependent. The signal strength of the sensor changes exponentially with its distance to the soil. Measurement also depends on the penetration depth of the field which is mainly affected by the geometry parameter used in the sensor design. The fringing electric field distributed beyond the penetration depth is weak. Therefore the sensor only measures the property of the adjacent soil.

This work will discuss the effect of the numbers of FEF fingers and excitation frequency when designing the FEF elements for measuring soil moisture level.

\section{RESEARCH SUMMARY}

The capacitance value from FEF element can be calculated from the formula derived by the conformal mapping method produced by the Schwarz-Christoffel transform [1], [2]. This mapping method shows the transition from parallel plate 
capacitor to fringing field capacitor as shown in Fig. 2. From this mapping, the FEF capacitance value is consist of two external capacitance $(\mathrm{Ce})$ and $(\mathrm{N}-2)$ internal capacitance $(\mathrm{Ci})$ as shown in Fig. 3 below. Thus, the calculation will be:

$$
\mathrm{CFEF}=2 \cdot \mathrm{Ce}+(\mathrm{N}-2) \cdot \mathrm{Ci}
$$

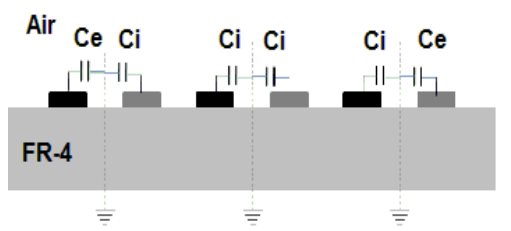

Fig. 3. Capacitance inner (Ci) and external (Ce).

The capacitance also is calculated for FEF element that has more than one finite dielectric layer as shown in Fig. 4 below. Thus, the calculation $\mathrm{Ci}$ and $\mathrm{Ce}$ when more than one finite layer is taking into consideration will be:

and

$$
\mathrm{Ce}=\mathrm{Ce}(\text { air })+\mathrm{Ce}(1)+\mathrm{Ce} \text { (substrate) }
$$

$$
\mathrm{Ci}=\mathrm{Ci} \text { (air) }+\mathrm{Ci}(1)+\mathrm{Ci} \text { (substrate) }
$$

These calculations method was derived from the Schwarz-Christoffel transform to FEF capacitance as discussed on [3]-[5].

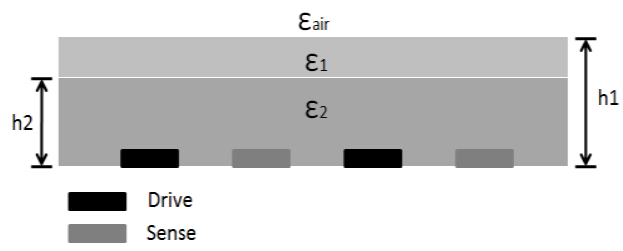

Fig. 4. Multi-dielectric layer on FEF elements.

To make this capacitance work, the drive electrode will be supplied with frequency. In this work, $100 \mathrm{kHz}$ to $2 \mathrm{MHz}$ will be supplied to the electrode. The behavior of both parameters will be studied in this work by using Cocopeat soil as the material under test (MUT).

\section{MATERIAL AND METHOD}

The two electrodes that perform as FEF element are design and printed on FR-4 type PCB material. The electrode pattern is design to achieve the optimum capacitance value with the given outlines. The parameter that is important for the FEF design is the pattern width (W), length (L), spacing $(\mathrm{S})$, and the numbers of fingers $(\mathrm{N})$ as shown in Fig. 5.

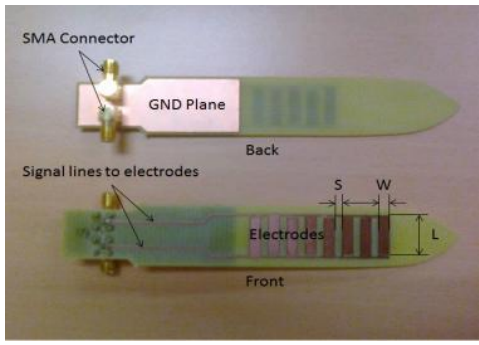

Fig. 5. FEF element.
In this work, we prepared five types of FEF element which consists of 5 to 9 finger patterns. The signal pattern from SMA connector to electrodes are kept as $50 \mathrm{ohm}$ as possible to maintain the signal integrity to avoid any loss or distortion [6]. Due to that, the PCB impedance is designed by controlling the PCB thickness, track width and adding GND plane underneath the track to keep $50 \mathrm{ohm}$ impedance.

The preparation of soil with pre-define VWC is almost impossible without a proper preparation and procedure. Proper procedure will help to reduce the error in the prepared soil. There are three steps detailed below:

\section{A. Calculate the Bulk Density of Dry Soil}

To calculate the bulk density of dry soil, the soil need to be bake to ensure it is $100 \%$ dry and the weight (W) is measured. Then measure the area (A) of the container being use and measure the height $(\mathrm{H})$ of soil in the container after it been compressed. With the (A) and (H) value, the volume $(\mathrm{V})$ of dry soil is calculated. The bulk density (BD) of dry soil is then calculated as:

$$
\mathrm{BD}(\text { DrySoil })=\mathrm{W}(\text { DrySoil }) / \mathrm{V}(\text { DrySoil })
$$

\section{B. Preparing Wet Soil for VWC Test}

The amount of water, $\mathrm{V}$ (Water) needed to prepare target VWC can be calculate as:

$$
\mathrm{V}(\text { Water })=\text { Target VWC } \times \mathrm{W}(\text { DrySoil }) / \mathrm{BD}(\text { DrySoil })
$$

\section{Actual VWC Measurement}

The actual VWC measurement is conducted and recorded by an external device to know the current VWC value of soil before it can be used.

The measurement setup is consist of five types FEF elements (5-9 finger FEF elements), five types MUT, LCR meter and two coaxial cable to supply excitation signal and read the capacitance.

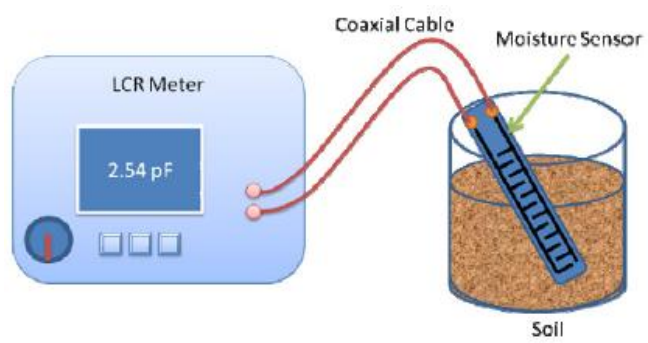

Fig. 6. Test setup for measuring capacitance versus soil VWC

In this work, assumption has been made that the moisture of dry soil is an equal with the moisture on air. Thus, the measurement of each FEF elements for $0 \% \mathrm{VWC}$ is by measuring the moisture content of the air. For $100 \%$ VWC, the FEF elements are tested by put it into the DI water and the prepared MUT was used to test FEF elements under $20 \%, 30 \%$ and $40 \%$ VWC. The FEF elements are inserted into five different area of soil with remain the same height. Then, the average value was plotted on the graph to show the relation of different VWC for each FEF samples. 


\section{RESULT AND DISCUSSION}

During the testing, changes in VWC would change the capacitance. These changes are recorded from $100 \mathrm{kHz}$ to 2 $\mathrm{MHz}$ for each type of FEF elements that have a different numbers of FEF fingers design. Result for the experiment conducted is as shown in Fig.7-11 below.

Along the frequency range, the capacitance value of \#5, \#6, and \#7 fingers FEF elements on air is almost linear and it is at the lowest capacitance level in the graph. The capacitance value for a $100 \%$ VWC MUT is the highest level. While the others moisture level, it is populated in between dry soil and $100 \%$ VWC except for \#8 and \#9 fingers FEF elements. At some frequency, the capacitance lines is very close to each other and the measurement of soil moisture will be difficult because there is no room for tolerance.

The calculation discussed in (1), (2) and (3) suggested that the capacitance value should increase from $0 \%, 20 \%, 30 \%$, $40 \%$ VWC until archived it saturation point proportionally. From the result, this can be seen at $900 \mathrm{kHz}$ frequency value for \#5, \#6 and \#7 fingers FEF elements, but the tolerance is very small. In the other hand, the results for \#8 and \#9 fingers FEF element does not achieve that and some of it reading a negative capacitance value. This is related to the complex dielectric constant of soil mixture. In general, it is a function of: 1) frequency, temperature and salinity, 2) the total VWC, 3) the relative fractions of bound and free water (related to the soil surface area per unit volume), 4) the bulk soil density, 5) the shape of the soil particles, and 6) the shape of water inclusions [8]. The dielectric behaviors of soil are represented by:

$$
\varepsilon=\varepsilon^{\prime}+\mathrm{j} \varepsilon^{\prime \prime}
$$

where imaginary part $\varepsilon^{\prime \prime}$ is known as dielectric loss, $\varepsilon^{\prime \prime} / \varepsilon^{\prime}=$ $\tan \delta$ is the loss tangent, and $\delta$ the loss angle.

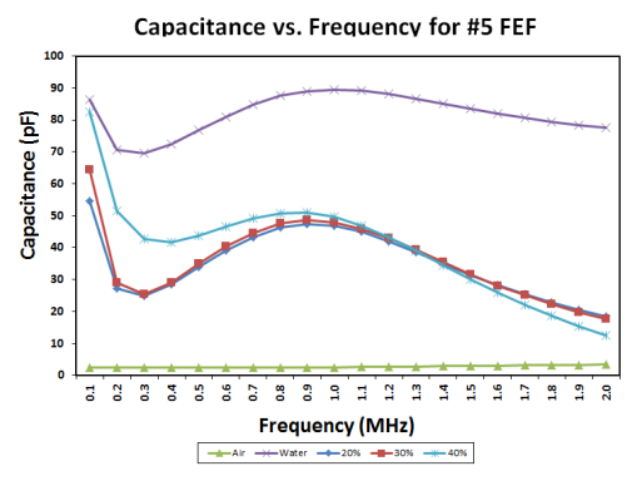

Fig. 7. Results for \#5 fingers FEF.

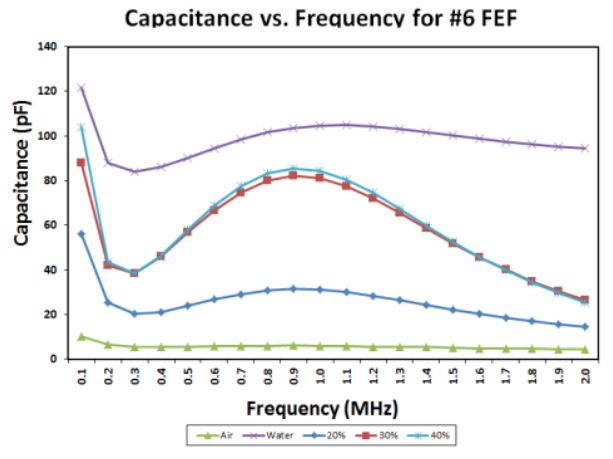

Fig. 8. Results for \#6 fingers FEF.

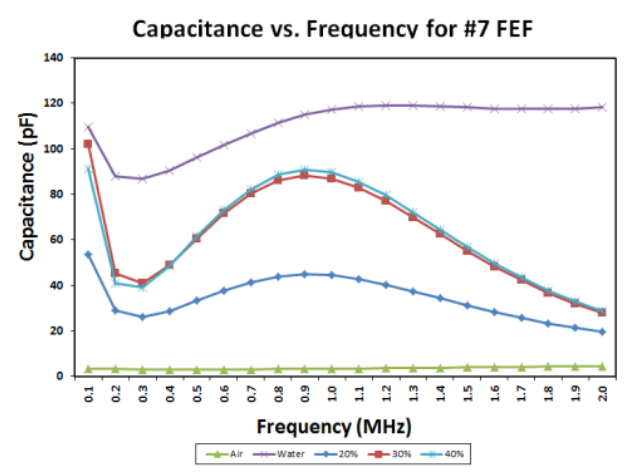

Fig. 9. Results for \#7 fingers FEF.

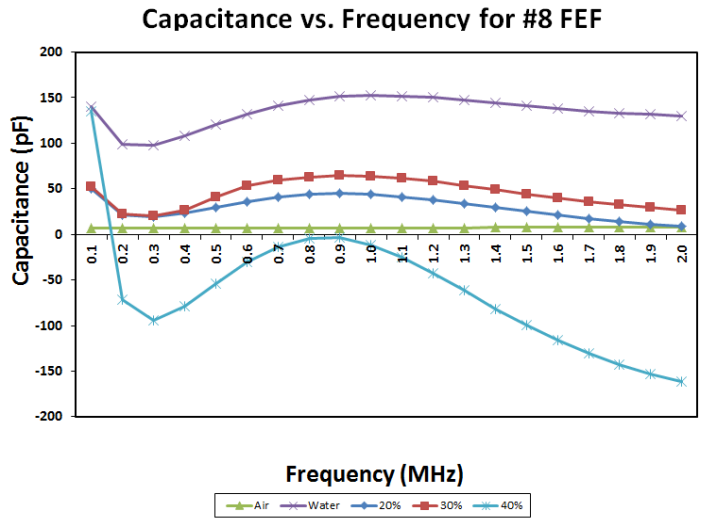

Fig. 10. Results for \#8 fingers FEF.

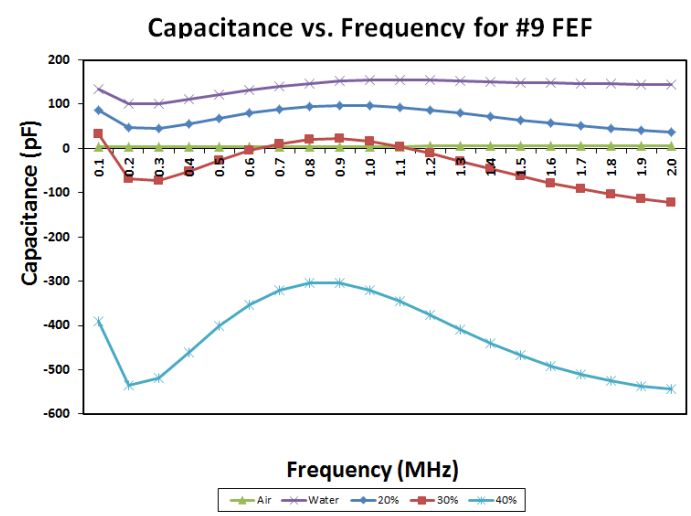

Fig. 11. Results for \#9 fingers FEF.

The numbers of study carried out by Hoekstra and Delaney (1974), Wang and Schmugge (1980), Hallikainen et al. (1985) showed that soil texture have an effect on dielectric constant behavior over frequency. The study also showed that the dielectric constant is related to the behavior of water being added to the dry soil. This behavior was explained by the transition of bound water to free water of the dry soil when water is added into it. In a dry soil, absorbed cations are tightly held by negatively charged particle surfaces composed predominantly of clay. When water is slowly added into the system, salt precipitates go into the solution, and the adsorbed cations partially diffuse into the solution adjacent to the particle surfaces. In a low frequency, the ionic conductivity of saline water may effect on the loss factor $\varepsilon$ ". Consequently, high soil salinity may significantly influence the dielectric properties of wet soils.

This may happened to the result of \#8 and \#9 fingers FEF element because when the numbers of fingers increase, the 
sensing area become larger. Due to the gravity effect, water content in each high of the MUT is not uniform. Thus, the soil might have higher salinity contain in the bottom side compared to the higher side. The high soil salinity may significantly influence the dielectric properties of wet soil that may results a negative capacitance value for the higher VWC as shown in Fig. 10 and Fig. 11.

Fig. 12 shows the relation between capacitance versus VWC for the best result in this study which is \#6 fingers FEF element. At $900 \mathrm{kHz}$, the increase of capacitance value is proportional with the VWC value. This result shows two different slope gradients: 1) $0 \%$ to $6 \% \mathrm{VWC}$ and 2) $6 \%$ to $100 \%$ VWC. The first slope is when the moisture in soil is in bond water stage and the other one is when in free water stage where the water content in soil is above the transition level $\mathrm{W}_{\text {T. }}$

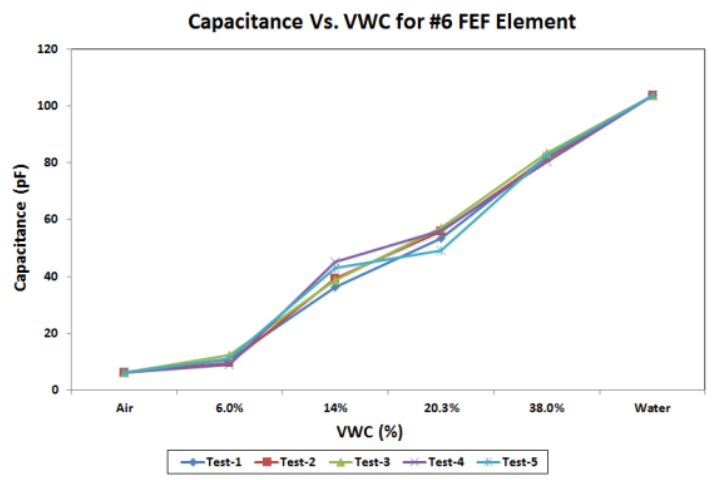

Fig. 12. Graph for \#6 fingers FEF (Capacitance vs. VWC).

\section{CONCLUSION}

This study shows the relationship of the numbers of FEF element fingers and operating frequency at low frequency with regard to the VWC of soil. In this work, the suitable frequency to be used to excite FEF element is at $900 \mathrm{kHz}$ and the element that is good for this application is \#6 fingers FEF element. Results at Fig. 12 shows there is a small tolerance with the numbers of test on the same MUT. The soil moisture measurement will take the second slope as it shows the real water content in soil.

\section{ACKNOWLEDGMENT}

The author would like to thank the staff members that fabricate the prototypes and advices along this process. This work is for Master Degree completion in Master of
Manufacturing in Islamic International University of Malaysia and sponsored by MIMOS Berhad.

\section{REFERENCES}

[1] N. Eidenberger and B. G. Zagar, "Capacitive sensor design utilizing conformal mapping methods," International Journal on Smart Sensing and Intelligent Systems, vol. 5, no. 1, pp. 36-56, March 2012.

[2] T. Sun, N. G. Green, and H. Morgan, "Electric field analysis using Schwarz-Christoffel mapping," Journal of Physics: Conference Series 142, pp. 1-6, 2008, DOI:10.1088/1742-6596/142/1/012029.

[3] S. S. Gevorgian, T. Martinsson, P. L. J. Linner, and E. L. Kollberg, "CAD models for multilayered substrate interdigital capacitors," IEEE Trans. on Microwave Theory and Technique, vol. 44, no. 6, June 1996.

[4] R. Igreja and C. J. Dias, "Analytical evaluation of the interdigital electrodes capacitance for a multi-layered structure," Sensors and Actuators A, vol. 112, pp. 291-301, 2004.

[5] E. Chen and S. Y. Chou, "Characteristics of coplanar transmission lines on multilayer substrates: Modeling and experiments," IEEE Trans. on Microwave Theory and Techniques, vol. 45, no. 6, pp. 939-944, June. 1997.

[6] H. W. Johnson and M. Graham, High-Speed digital design: A handbook of black magic, $1^{\text {st }}$ ed. Prentice-Hall PTR, 1993, pp. 133-188.

[7] J. Behari, "Microwave dielectric behavior of wet soils," Remote Sensing and Digital Image Processing, Springer, vol. 8, pp. 10, 2005.

[8] Chukhlantsev, A. Alexander, "Microwave radiometry of vegetation canopies," Advances in Global Change Research Series, vol. 24 Chapter 2, pp. 23-29, 2006.
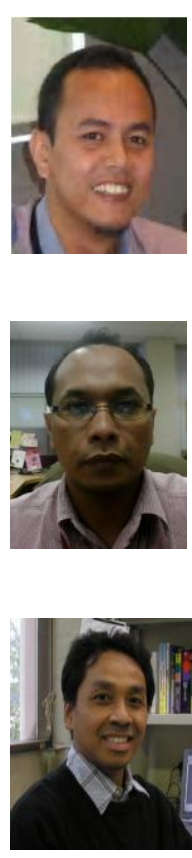

Mohd Farizul Azman was born in Malaysia, in 1976. He received an Advanced Diploma at Nagano National Technology College in Japan in 1999. He is working at MIMOS Berhad as a Senior Engineer and responsible for PCB design and fabrication for MIMOS product. He is currently studying a Master of Manufacturing in International Islamic University of Malaysia. $\mathrm{He}$ is certified PCB designer from IPC from 2011.
Azmi Yahya was born in Malaysia, in 1972. He received a Degree in Electrical Engineering at Nagano University Technology of Malaysia in 2012. He is working at MIMOS Berhad as a Technician and responsible for PCB design and fabrication for MIMOS product.

Hadi Purwanto was graduated from Institute Technology Sepuluh Nopember, Indonesia and completed his PhD in Metallurgy at Tohoku University, Japan. He is currently a lecturer at the Department of Manufacturing and Materials Engineering, International Islamic University Malaysia. His research area of interest are Iron making, Non-destructive testing, Biomass, Waste materials and energy processing. 